\title{
Exploring Pre-service Biology Teachers' Informal Reasoning and Decision-Making About COVID-19
}

\author{
Cigdem Han-Tosunoglu ${ }^{1} \cdot$ Ferah Ozer $^{2}$
}

Accepted: 4 August 2021 / Published online: 27 August 2021

(c) The Author(s), under exclusive licence to Springer Nature B.V. 2021

\begin{abstract}
The world has been fighting with the novel COVID-19 pandemic, which has scientific, societal, and ethical components, and thus it can be classified as one of the most challenging socio-scientific issues (SSI) of our era. The pandemic required individuals to make decisions on a variety of issues, and these decision-making processes are highly related to informal reasoning and individuals' scientific literacy (SL). Thus, this paper aims to investigate the $N=26$ pre-service biology teachers' informal reasoning and decision-making modes within the real-time and dynamic COVID-19 pandemic context. The present study revealed that most of the participants made rationalistic based decisions about COVID19 and social isolation. Moral-based decision-making, which is second-highest frequency among all decision-making modes, is also specific to COVID-19 and social isolation. Furthermore, the participants utilized different arguments while self-reasoning on the issue and convincing someone of their ideas about social isolation and COVID-19.
\end{abstract}

\section{Introduction}

Scientific literacy, which is a widely used concept in the literature, is a favorable outcome in science education. The literature embodies numerous aspects of this concept and the characteristics of a scientifically literate person (e.g., DeBoer, 2000; Eisenhart et al., 1996; Hurd, 1998). Norris and Phillips (2003) have provided a clear picture of what scientific literacy is and listed the following features: (1) knowing what counts as science and how science differs from nonscience, (2) knowledge needed for participating in science-related social issues, (3) knowing the risks and benefits of science, and (4) being able to think critically about science.

In order to develop the aspects of scientific literacy in school science, socio-scientific issues (SSIs) offer valuable context (Sadler \& Dawson, 2012). SSIs are defined as the issues that emerge from the interaction of science and society. Also, the issues, or societal

Cigdem Han-Tosunoglu

cigdem.han@marmara.edu.tr

Ferah Ozer

ferah.ozer@boun.edu.tr

1 Department of Biology Education, Faculty of Education, Marmara University, Istanbul, Turkey

2 Department of Science Education, Faculty of Education, Bogazici University, Istanbul, Turkey 
challenges based on science, provide the kinds of real-world situations that students ought to have opportunities to consider as they learn science (Zangori et al., 2020). Many science educators have advocated that individual practices of decision-making about societal issues are fundamental aspects of scientific literacy (e.g., Kolstø, 2006; Zeidler et al., 2002; Zeidler \& Keefer, 2003).

To date, SSI frequently stems from biotechnological developments such as cloning, stem cells, and genetically modified foods and environmental challenges such as global climate change (Sadler \& Zeidler, 2005; Wu \& Tsai, 2007; Yang \& Anderson, 2003). Furthermore, social issues related to health that directly affect people's lives have recently become noteworthy globally. Health is not only a physical notion whereby diseases are attributed to external causes identifiable by scientific means, but also a psychological construct that is linked to individual cognition, perceptions, attitudes, and beliefs, which are influenced by social and cultural norms and in turn influence how people view and manage their lives (Lyons \& Chamberlain, 2006). This multidimensional nature indicates that making health decisions at both personal and societal levels is difficult to evaluate solely based on science (Lee, 2012).

New infectious diseases (such as SARS, MERS, ZIKV, and avian flu) that emerged in the last century were the leading health-related social issues. Currently, a new outbreak has emerged, that is COVID-19 (SARS-Cov-19 Coronavirus disease) and people have been struggling with it all around the world. According to World Health Organization (WHO) (2020), "COVID-19 is the infectious disease caused by the most recently discovered coronavirus. This new virus and disease were unknown before the outbreak began in Wuhan, China, in December 2019. COVID-19 is now a pandemic affecting many countries globally." After the WHO's declaration of COVID-19 as a pandemic, people from all around the world faced with its impacts on daily lives as well as social, economic, health, etc. related problems stemmed. To date, people continue to cope with the dilemmas and problems related to COVID-19. The issue has been considered an ill-structured problem and controversial at the same time (Reiss, 2020), which requires scientific evidence-based reasoning and decision-making. It also requires the use of scientific concepts that have social consequences and ethical components as well as some degree of moral reasoning. In terms of these essential characteristics (Zeidler, 2014), COVID-19 can be classified as SSI (Reiss, 2020).

Scientific literacy is crucial to tackle with infodemic (Saribas \& Çetinkaya, 2020), that has been defined by WHO (2020) as "infodemic is too much information including false or misleading information in digital and physical environments during a disease outbreak." Managing infodemic requires all individuals to critically evaluate the claims about the issue and make informed decisions regarding health (Rennie et al., 2001). From this perspective, understanding of informal reasoning throughout the infodemic is more essential since decision-making in this process involves not only constructing and evaluating arguments on the issue, but also ability to understand uncertainty in science. The uncertainty in science and overabundance of information affects public decision about the issue (Saribas \& Çetinkaya, 2020). To improve individuals' informed decision-making about science related issues, public understanding of science should be promoted.

In this context, COVID-19 presents a real-time, health-related SSI which has potential to reveal individual's pattern of informal reasoning. When working on SSI, informal reasoning appears to be a vital thinking skill (Fang et al., 2019). Unlike formal reasoning (scientific reasoning) which uses mathematical and logic rules to solve well-formulated problems, informal reasoning for decision-making in SSI requires learners to construct and evaluate arguments on ill-defined problems (Sadler, 2004). Zohar and Nemet (2002) 
describe the concept of informal reasoning: "It [informal reasoning] involves reasoning about causes and consequences and about advantages and disadvantages, or pros and cons, of particular propositions or decision alternatives. It underlies attitudes and opinions, involves ill structured problems that have no definite solution, and often involves inductive (rather than deductive) reasoning problems" (p. 38). Since informal reasoning tasks implicitly indicate the assumptions, the conclusions of the arguments in informal reasoning may not be demarcated. As a result, informal reasoning is mostly utilized to make decisions about the circumstances in which any clear-cut conclusions are present (Shaw, 1996). In this study, decision-making modes, self-reasoning modes and persuasion means were used as indicators for examining individuals' informal reasoning. In this regard, decisionmaking modes describe patterns of reasoning used to negotiate and resolve the issue. Selfreasoning modes refer to factors that may influence individuals' arguments on the issue (Ozturk \& Yilmaz-Tuzun, 2017). Lastly, persuasion means are utilized to persuade other people in the case of opposition to individuals' arguments or ideas (Liu \& Lawrenz, 2018).

The purpose of the study is to investigate pre-service science teachers' (PSTs) informal reasoning and decision-making patterns regarding COVID-19. One of the unique characteristics of the study is the issue being selected. The issue of COVID-19 is a real-time, dynamic, and global problem that affects people all around the world. Individuals have been quickly experiencing the consequences of both their own decisions (such as wearing mask, using sanitizer, social distancing) and political decisions (such as curfew or lockdown, economic issues) regarding COVID-19. Thus, the issue provides an opportunity for individuals to generating multitude different arguments and a context to deal with realworld problem they have encountered in daily life. Also, the real-time health issue enables the individuals to simultaneously weigh up scientific evidence and psychological factors arising from the problem (Lee, 2012). In this regard, COVID-19, the current pandemic, provides an effective situation for individuals to experience the impact of their decisions on the issue. Most of research in SSI has focused on local and hypothetical issues (e.g., floating vessels into rivers in Taiwan, Fracking in Pavilion Wyoming, and Branville Bay ecosystem) (Ladachart \& Ladachart, 2021; Romine et al., 2017) or long-term nature issues such as GMF, climate change and nuclear power plant (Sadler \& Zeidler, 2005; Wu \& Tsai, 2007; Yang \& Anderson, 2003) while exploring informal reasoning of individuals. Few studies used health issues to examine individuals' informal reasoning (Lee, 2007; Lee \& Grace, 2012; Lundström et al., 2012; Wiblom et al., 2020). The most important characteristic of students' informal reasoning about health issues is its multi-dimensional nature. These dimensions included personal and public health, economic, intuitive, risk-oriented, and science.

Another characteristic of the study is the population being studied. Much of the science education research related to informal reasoning and SSI has been conducted with students (e.g., Walker \& Zeidler, 2007; Wu \& Tsai, 2007; Zohar \& Nemet, 2002). Few studies have focused on pre-service teachers to get their ideas about SSIs (Lee et al., 2012; Ozturk \& Y1lmaz-Tuzun, 2017; Topçu et al., 2011). In the classroom context, addressing SSIs is generally characterized by the students' use of informal reasoning (Sadler, 2004; Sadler \& Zeidler, 2005), argumentation process, and decision-making about the issue (Wu $\&$ Tsai, 2007). The literature reveals that teachers struggle with transferring SSI into their classroom practices and teaching it effectively (Bayram-Jacobs et al., 2019; Tidemand $\&$ Nielsen, 2017). Thus, they should have sufficient knowledge and experiences on how to deal with SSI by using informal reasoning and argumentation processes (Jonassen \& Kim, 2010). Therefore, we believe that it is necessary to explore PSTs' informal reasoning, namely how PSTs negotiate and resolve SSI, because the understanding of PSTs' 
reasoning process gives evidence for training and supporting PSTs on the SSI instruction. In other words, it can provide information to develop science teacher professional development (Ozturk \& Y1lmaz-Tuzun, 2017). Teaching COVID-19 as an SSI can be likely spaced in the biology classroom because of its content. Thus, addressing informal reasoning of PSTs is more important than the other teachers. As potential candidates for teaching how to become a scientifically literate person and how to decide on issues related to COVID19, PSTs represent a particularly important population in terms of understanding how they think about and negotiate COVID-19 as a science based social issue. Specifically, the study was based on the following research questions:

1 What are the-decision-making modes of pre-service biology teachers on a real-time SSI context, namely the COVID-19 pandemic?

2 What are the self-reasoning modes of pre-service biology teachers on a real-time SSI context, namely the COVID-19 pandemic?

3 What is the persuasion means of pre-service biology teachers on a real-time SSI context, namely the COVID-19 pandemic?

\section{Theoretical Framework}

\subsection{Informal Reasoning}

Reasoning is a method in which concepts and evidence are studied to draw conclusions in order to come up with new conclusions based on facts (Holyoak \& Morrison, 2005; Wason \& Johnson-Laird, 1972). It also is described as the method of development and assessment of opinions (Shaw, 1996). In the context of science education, scientific reasoning also refers to deductive reasoning distinguished by mathematical and logical principles. Learners are faced with clearly defined issues in these reasoning exercises, and they are instructed to believe that the propositions of issues are valid and to develop or accept only the most obvious conclusions (Evans \& Thompson, 2004). In addition, reasoners should avoid taking their historical experience and personal values into account and they will only seek to fix complex issues by using the given details (Evans, 2002; Evans \& Thompson, 2004). Nevertheless, while the outcomes of science can be interpreted in the form of traditional logic and reasoning, it has been suggested that the outcomes themselves arise from informal reasoning (Tweney, 1991). Educators have also indicated that most of the reasoning practices within classroom are informal by nature (Means \& Voss, 1996). Reasoning skills that are informal can also be of great value, and educational scholars have extensively emphasized the importance of informal reasoning.

Informal reasoning involves considering ill-structured and open-ended problems and drawing inferences from uncertain premises (Kuhn, 1991). Informal reasoning can be broadly characterized by inductive reasoning, because deductive reasoning requires welldefined problems and clear premises. Individuals do not need additional information or background knowledge to arrive at the correct answer for formal reasoning (Evans \& Thompson, 2004). However, informal arguments may include premises and conclusions which are not clearly defined (Shaw, 1996). Thus, the validity of informal arguments can rarely be ensured by deductive reasoning (Ohm, 2005). Formal reasoning focuses on whether conclusions are valid; informal reasoning relies on the quality of premises, and whether conclusions are evidence-based (Teig \& Scherer, 2016). The dual procedure 
theories may be used to clarify the cognitive function of informal arguments or reasoning (Evans, 2003).

The dual-process theories (Hogarth, 2005) state that two distinct cognitive systems are used by humans in their decision-making: an intuitive (tacit or implicit) system (type 1) and an analytical (deliberate or explicit) system (type 2). An intuitive system is used unconsciously, based on bias, and is easily affected by emotions associated with earlier experiences. In contrast, an analytical system is consciously used and comprised of logical and abstract thinking. The dual-process theories were adopted from the field of psychology to describe the possible mechanism behind individuals' SSI decision-making behavior (Böttcher \& Meisert, 2013; Wu \& Tsai, 2007, 2011).

When an individual encounters an ill-structured problem (like SSI), s/he may initially obtain relevant information from past experiences and use the intuitive system to create a preliminary mental model of the problem at hand. An intuitive decision may most likely be made after this. It is also possible that the learner may employ an analytical system to carry out logical thinking, modify the preliminary mental model and then carry out informed decision-making (Böttcher \& Meisert, 2013). This means that the intuitive system is the default mechanism, and that the analytical system would be employed when the existing situation requires thorough examination of all aspects of a situation. In this sense, both formal and informal reasoning have a common goal that is to produce new knowledge by considering existing information through the dual process theory (Teig \& Scherer, 2016).

There are several outcomes of informal reasoning process (Fig. 1). Decision-making and reasoning modes are the ones that are mostly investigated in the literature (Sadler \& Zeidler, 2005; Wu \& Tsai, 2007; Yang \& Anderson, 2003) Decision-making modes serve as an indication whether the participants could provide evidence for their decisions (evidence-based decision-making) or their decisions were made based on immediate feelings and responses (intuitive-based decision-making) while discussing and solving ill-defined problems. Reasoning mode represents interdisciplinary thinking with respect to employing knowledge from different perspectives when making decisions. The result of informal reasoning may be evaluated as critical skills for handling SSI (Liu et al., 2011).

The earlier research in the literature about informal reasoning on teachers and students led categories to emerge. These categories guide the studies conducted in the field of SSI to analyze participant responses in terms of variety of informal reasoning modes. For instance, for decision-making modes, rationalistic, emotive (Sadler \& Zeidler, 2005; Topcu et al., 2011), and intuitive (Wu \& Tsai, 2011) modes had emerged, whereas for reasoning

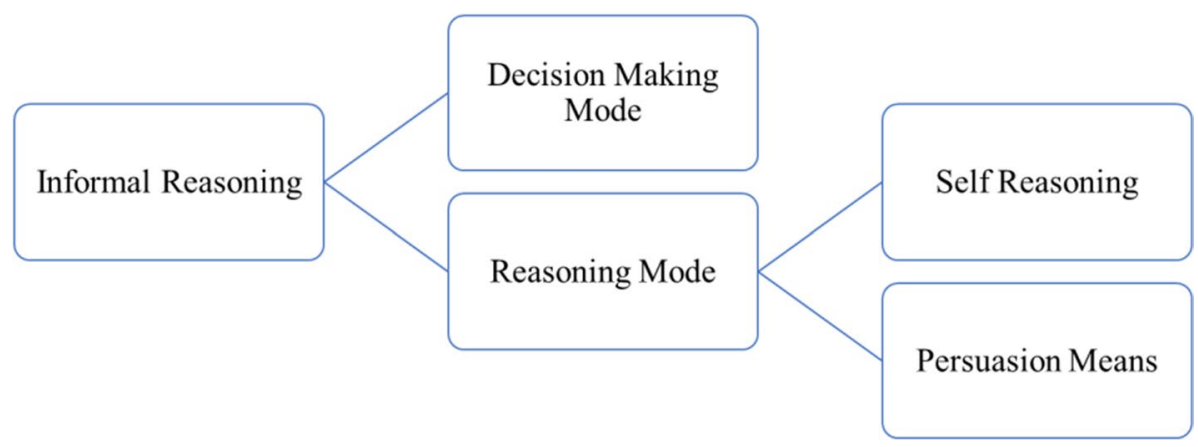

Fig. 1 The components of informal reasoning 
modes, economic oriented (Lee \& Grace, 2012; Ozturk \& Y1lmaz-Tuzun, 2017; Wu \& Tsai, 2007, 2011), risk perception, political oriented (Ozturk \& Y1lmaz-Tuzun, 2017), moralbased, and religious oriented (Topcu et al., 2011) were defined by the scholars.

However, different arguments are generally put forward by individuals when they are trying to convince others through argumentation. This is because they only try to acquire reasons to back their own perspectives and disregard the significance of coordinating the opinions of others. In addition, it is common for even those who are skilled in performing scientific reasoning to only concentrate on the superficial areas of evidence when developing or analyzing arguments (Liu \& Lawrenz, 2018). Thus, apart from decision-making modes and reasoning modes, persuasion means were utilized as indicators of informal reasoning process in this study.

\subsection{Informal Reasoning About SSI and Health Issues}

Socio-scientific issues refer to those issues that depend on scientific notions or problems, are of a controversial nature, discussed in public domains and often exposed to influences from political and social domains (Sadler \& Zeidler, 2005). Extensive debates have been carried out on SSIs in the society in the recent times, and at present, no straightforward and definite solutions have been obtained for them (di Sessa, 1993; Mason \& Scirica, 2006). Therefore, the public consistently comes across arguments from different sources that support conflicting perspectives. Competing arguments on SSIs can be suitably examined by moving beyond formal and logical thinking and performing reasoning that will enable them to acknowledge the innate intricacy of science (Kuhn, 1993; Sadler, 2004; Sadler et al., 2007).

Furthermore, it is difficult and challenging to be involved in SSIs as it consists of developing opinions, taking decisions at the personal or societal level, performing critical assessment of media reports (from where we obtain majority of our information on a daily basis), analyze claims, consider values, and perform moral and ethical reasoning. In addition, it may also require comprehending risk and probability to a certain extent. Hence, the process of informal reasoning, instead of formal reasoning, is typically used to characterize the discussion and resolution of SSIs (Sadler, 2004). Cognitive as well as affective elements are employed by informal reasoning, which is suitable when handling socio-scientific issues. Individuals come across socio-scientific issues, for example concerns regarding the use of mobile phone, consumption of genetically modified food or recycling of household waste. We need to make decisions at the societal level on climate change, population control, energy resources and quality and supply of water. The choices are not straightforward and give rise to ethical concerns. To make any decision, individuals need to weigh the risks and benefits against one another, put forward questions and analyze the integrity of information (Dawson \& Venville, 2009).

In the last century, individuals have been making efforts to make decisions for not only the issues that emerge with technological development (biotechnology issues), but also for issues concerning health (such as the pandemic flu). Being a socio-scientific issue, health poses significant challenges as well as opportunities for the future of humanity (Fensham, 2012). Over the previous century, the definition of health went through major changes, shifting from a conventional medical model that concentrated on the physical health of individuals to the bio-psychological model that asserts that health is affected by a combination of biological, sociological, and psychological factors (Lee, 2012). There are several health issues that can be considered SSIs (Ratcliffe 
\& Grace, 2003) as they are open-ended, poorly structured, generally controversial, and subject to varied viewpoints and solutions (Sadler \& Zeidler, 2004, 2005).

SSIs related to health are inherently multidimensional. Specifically, addressing the complicated, unclear dynamics of zoonotic disease calls for making such social and political lives explicit in approaches that intend to achieve triangulation instead of integration, and plural and conditional instead of singular kinds of policy advice (Leach \& Scoones, 2013). A strong argument is presented by Leach and Scoones (2013) in favor of an interdisciplinary method in handling zoonoses such as COVID-19. Similarly, people need to utilize different reasoning modes for addressing COVID-19. By nature, COVID-19 can be presented as SSI (Reiss, 2020), because individuals' decisions about COVID-19 have been determined through the interaction of scientific knowledge, sociocultural environment, ethical issues, and psychological context. The issue also provides an effective context for discussing public health, vaccination and impact of economics and politics on health issues in school science.

Recently, numerous studies have been conducted to represent individuals' informal reasoning on SSI (Sadler \& Zeidler, 2005; Wu \& Tsai, 2007; Yang \& Anderson, 2003). The most of studies regarding decision-making on SSI have focused on nuclear energy (Jho et al., 2014; Ozturk \& Y1lmaz-Tuzun, 2017; Yang \& Anderson, 2003; Wu \& Tsai, 2007) and genetic engineering (Sadler \& Zeidler, 2005; Topçu et al., 2011). These issues are of long-term nature. Therefore, individuals do not likely have an opportunity to experience the effect of the discussion about the topic at the end of the teaching in school (Fooladi, 2020). Due to the nature of the issues, most of the arguments produced by individuals through the discussion of SSI have become hypothetical. In present pandemic, COVID-19 provides an effective context for individual to experience the effect of their decisions on the issue, since we are in the middle of the experiment while we carry on with our lives. Few studies (Lee, 2012; Lee \& Grace, 2012) have utilized health issues while examining student's decision-making on SSI. To our knowledge, only a couple of studies were conducted in a real-time context (Kolstø, 2006; Lundström et al., 2012).

Lee (2007) focused on middle school students' informal reasoning regarding banning of smoking in the restaurants. The results showed that most of arguments are based on intuitive reasoning and lack empirical support. Moreover, the students tended to maintain social stability more than personal or public health. Lee and Grace (2012) employed the issue of central slaughtering of chickens to protect citizens from avian flu by minimizing avian-human contact. They concluded that students were capable of multi-perspective thinking. Public and personal health, science, economic, sociocultural, and environmental perspectives were more important in students' decision-making. Lundström et al. (2012) examined of how students made their decision on whether to vaccinate themselves against the new influenza or not. The results showed that the students were able to develop different arguments and make decisions by drawing from public and personal health and science perspectives similar to Lee and Grace (2012) and risk oriented. Overall, students tend to focus on personal and public health and scientific perspectives when reasoning on the issue which directly influence themselves (e.g., avian flu).

In addition, individuals' decision-making process influenced by the nature of SSI and the context that the issue takes place (Wu \& Tsai, 2011). Health issues such as COVID-19 are more related to our personal lives rather than long-term nature issues. Thus, decisionmaking on health issues is likely to evoke psychological factors in place of rationalistic considerations (Lee, 2012). 


\section{Method}

\subsection{The Context of the Study}

This study has been conducted in Turkey. Turkey provides a special research perspective in the context of geography, society, politics as well as religious history, compared to other western European and US sites. The results obtained from research pertaining to informal reasoning and decision-making regarding SSI may be diverse for different countries because of the diversity of characteristics of each country (Ozturk \& Y1lmaz-Tuzun, 2017; Topçu et al., 2011). In short, cultural issues can be significant factors of individuals' arguments when tackling SSIs (Lee \& Grace, 2012; Zeidler, et al., 2005).

In terms of pandemic context, the country had faced its first COVID-19 case on March 11, 2020 and the first related death to COVID-19 occurred on March 17, 2020. Prior to the first detected case, the Turkish Ministry of Health established a COVID-19 Scientific Advisory Committee and this scientific committee aimed to provide guidance for policymakers, to decide what measures and restrictions will be taken throughout the country, conduct risk assessments, introduce case definitions, form medical guidelines as well as guiding patients' care and treatments (Demirbilek et al., 2020). Following week starting from March 16, all the K-12 level schools and universities were closed, and the type of instruction was designated as remote until further notice. The same week additional restrictions were announced by the Government such as cancellation and prohibition of mass gatherings, limitations on the visits for long term care facility residents, restaurants transforming their services only for take-away, border closures, intercity travel restrictions, quarantine, and stay-home restrictions for the whole country (Güner et al., 2020). Immediately after the official closure of the schools, towards the end of March 2020, the data of the current study were collected. As of April 1, in Turkey, there were 15.679 cases detected in which it was rising each day and 277 people lost their lives due to COVID-19 (Turkish Ministry of Health, 2021). On May 4, 2020, Government announced that with the decreases in the number of new cases (daily 3.500 approximately) as well as death rolls, normalization steps could be taken incrementally starting from the end of May (Turkish Ministry of Health, 2021). Followingly, on June 1, 2020, many of the restrictions were lifted and returning to normal daily life was encouraged by taking necessary precautions advised by the officials.

\subsection{Participants}

Participants of the study were $N=26$ (male: 2, female: 24); 6 junior (3rd year) and 20 senior (4th year) pre-service science teachers (PSTs) who are enrolled in a science teaching program majoring in Biology at a state university located in Istanbul, Turkey. Their age ranged between 20 and 23. All the participants completed their required science content courses at their program.

\subsection{Procedure}

This study is a qualitative exploratory study that explored a group of pre-service science teachers' informal reasoning and decision-making about COVID-19 descriptively. The study was conducted in accordance with ethical conduct. Initially, a department-wide announcement including the information about the timeline and expectations of the study 
was made for the recruitment by the first author. Then, individual online meetings were set with those who are interested to participate to the study. Afterward, the written individual consent forms stating their voluntary participation in the study was gathered from the participants. The names of the participants were anonymized.

\subsection{Data Collection}

\subsubsection{Interviews Assessing of Informal Reasoning}

Semi-structured interviews were conducted to assess self-reasoning modes and to determine decision-making modes of PSTs about COVID-19 pandemic. The interviews were conducted by the first author, who is an experienced SSI researcher and a faculty member at the university, through online platforms due to COVID-19 pandemic nationwide stayhome/lockdown orders throughout the process, in March 2020. Each lasted between 20 and 30 min. Following the interviews' completion, the authors transcribed them verbatim into a qualitative data analyzing software.

The participants' informal reasoning about COVID-19 was assessed through the questions of the questionnaire developed by Wu and Tsai (2007). Although the original questionnaire was developed as a paper-and-pencil instrument, the questions were also appropriate for use in interviews since they were open-ended. Through these questions, the participants' informal reasoning positions regarding decision-making and their reasoning modes were explored.

At the beginning of the interviews, a passage (please see Appendix) was given to PSTs and were asked to read the passage. Then they were expected to respond to the questions below. The passage was structured as a typical SSI text, presenting the complex and multidimensional structure while including dilemmas from multiple perspectives in an objective manner while allowing to introduce of different aspects of the issue (Sadler, 2004). In line with this, PSTs initially were confronted with a brief background of COVID-19 pandemic, latter the details about the current situation in different countries, policies, and management of pandemic in certain countries were provided and eventually, the impact on economic, social, and psychological life was presented. Moreover, during the interviews, the definitions of the terms such as social distancing, isolation, and quarantine were explained in detail to the participants. Nevertheless, should the participants have more questions or needed more explanations, the guidelines prepared by the Turkish Ministry of Health Covid-19 Advisory Scientific Committee were referred.

The questions and the purposes for including each item are stated below:

1. COVID-19 pandemic has been spreading all over the world, including in our country. Do you agree with the idea that social distancing and isolation and quarantine are necessary precautions for preventing COVID-19 contagious? Why? (Assessing pre-service teachers' decision-making modes whether rationalistic/emotive or intuitive and their self-reasoning modes on the novel COVID-19 pandemic)

2. If you want to convince your friend with your position, what arguments you will propose to convince him/her? (To evaluate pre-service teachers' reasoning modes in terms of persuasion and ability to generate supportive arguments for their positions)

3. If someone holds an opposite position with you on this issue, what arguments he/ she may have? (Assessing pre-service teachers' reasoning modes in terms of persuasion and ability for generation of counterarguments) 
4. According to the arguments you have proposed in question 3, can you state your opposing ideas to justify your position? (Evaluating pre-service teachers' reasoning modes in terms of persuasion and ability for generation of rebuttals)

\subsection{Data Analysis}

Participants' ideas and arguments were explored in a manner consistent with inductive data analysis as described by Lincoln and Guba (1985), and the constant comparative method described by Glaser and Strauss (1967). The inductive analysis involves the identification and coding of fundamental meaning extracted from participants' answers. Categories were described with oral explanations, in accordance with the research questions. Inductive analysis facilitates the emergence of new and undiscovered codes and categories from data during in vivo coding (Patton, 1990). The reasoning leading to descriptive as well as explanatory categories can be prompted by making comparisons between bits of data acquired from different sources (Lincoln \& Guba, 1985). For this reason, the researchers conducted open coding to evaluate the participants' reasoning modes using the constant comparison data analysis method.

Data analysis started with the transcription of the interviews. The second step of the analysis involved the coding of data. This step was carried out by two authors. To carry out the analyses, the first and second authors read and coded all the interviews independently. The existing frameworks (Sadler \& Zeidler, 2005; Wu \& Tsai, 2007; Yang \& Anderson, 2003) in the literature initially guided the coding; however, new themes also evolved during the coding process and included in the existing themes. For instance, along with the five existent categories of self-reasoning modes (e.g., Ozturk \& YilmazTuzun, 2017; Wu \& Tsai, 2007; Wu \& Tsai, 2011), a new category emerged namely psychological oriented. Moreover, apart from the existent self-reasoning modes a genuine self-reasoning mode category arose and was separately grouped into a new category that is called the persuasive means. To give an example, a participant (PST \#4) utilized moral-based and religious-oriented self-reasoning mode on COVID-19. When she comes to convince another person in the case of opposition to her arguments regarding COVID-19, she preferred to use evidence-based and moral-based reasoning mode. Even though some of the modes inside of the persuasive means were also found in the selfreasoning modes; novel categories such as experience-based, authority-based, evidence based were also generated. Table 1 presents both the existent categories that guided the coding process in this study (first column), new categories emerged in the current study (second column).

This step also allowed researchers to check the consistency, or lack thereof, between the participants' statements in response to different questions. Any inconsistency identified as a result of this analysis was noted and discussed by the researchers in the next step of the analysis.

The third step in data analysis was a comparison of coding conducted by two authors. In this step, two authors compared their coding in order to reach a consensus on the final themes. The inter-rater agreement rate of the authors was calculated as 0.90 and the discrepancies were resolved with an ultimate agreement.

The fourth step of data analysis was the quantification of the data. In this step occurrence of each code was examined in detail, then the data was quantified as frequency and percentiles to have a better sense of it. 


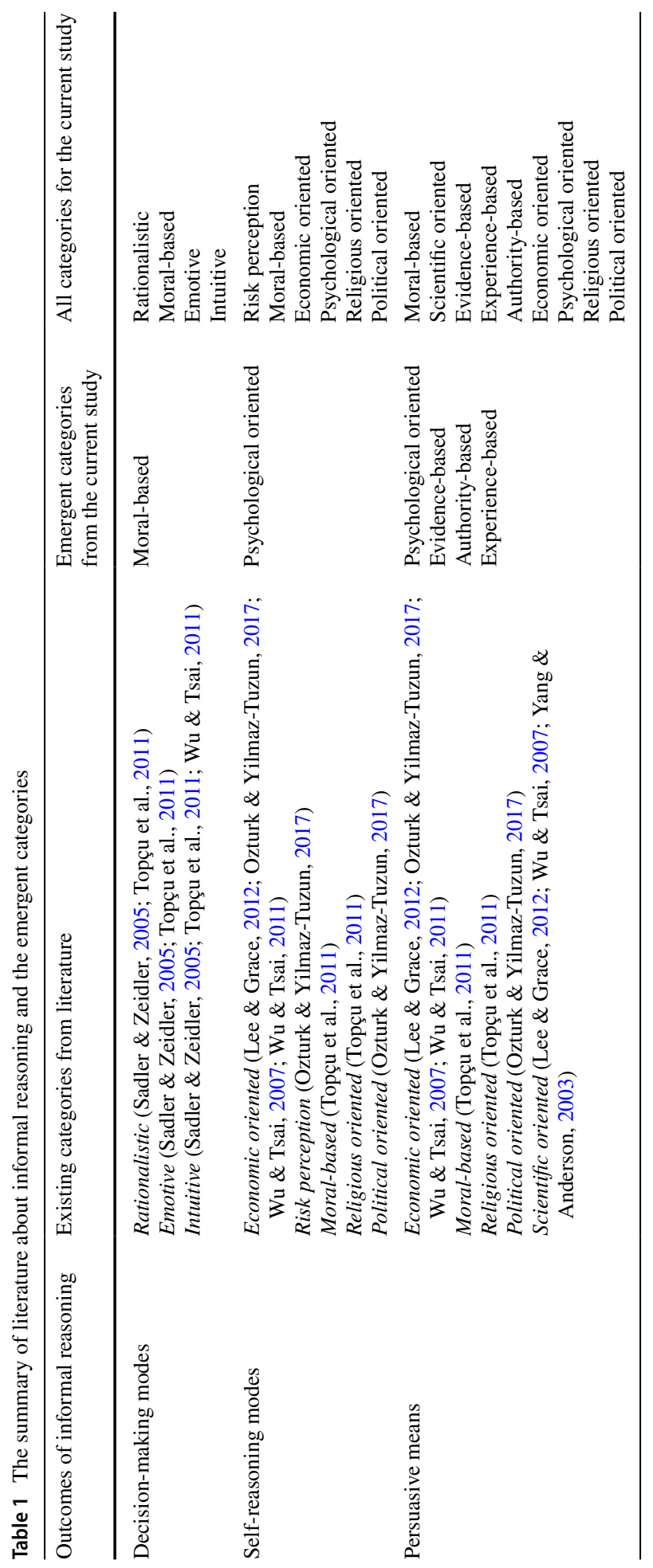




\section{Results}

The findings of the study are represented as the findings about "decision-making modes," "reasoning modes," and "persuasive means" as follows.

\subsection{Decision-Making Modes}

Responses to interview question \#1 were used to assess pre-service teachers' decisionmaking modes. And according to these responses, it was seen that most of the participants $(N=25)$ were in favor of social isolation. Table 2 shows the type of decision-making mode, its description, number of PSTs used this type, and number of references it was addressed within the mode. As seen in Table 2, the qualitative analysis revealed four categories for the decision-making modes: rationalistic $(N=24)$, emotive $(N=5)$, intuitive $(N=4)$, and moral based $(N=7)$. First three categories were identified by Sadler and Zeidler (2005). Moral based decision-making mode was observed as a new category in the present study. PSTavs that considered moral arguments when making decision on COVID-19. Table 2 presents the categories of decision-making modes and their descriptions. The example quotations regarding to particular types of decision-making modes of PSTs and content are provided below.

\subsubsection{Rationalistic Decision-Making Mode}

It was expected in rationalistic decision-making mode that participants use their logic to support their arguments and reason them (Sadler \& Zeidler, 2005). Accordingly, it was seen that the big majority of PSTs $(N=24)$ explained their decisions based on a rational justification about why isolation or staying at home is needed. They supported their arguments with logic, scientific knowledge, and by mostly referencing scientists' work. It was also seen from a number of the references $(N=31)$ that some PSTs used this type of mode more than once within their interview responses. Example quotations are provided below.

[PST \#1]: "Yes I agree professor; we should stay at home. We see on the news every

Table 2 Pre-service biology teachers' decision-making modes

\begin{tabular}{llll}
\hline $\begin{array}{l}\text { Decision-making } \\
\text { modes }\end{array}$ & Description & Number of PSTs & $\begin{array}{l}\text { Number of refer- } \\
\text { ences }\end{array}$ \\
\hline Rationalistic & $\begin{array}{l}\text { Individuals use rational patterns of thought to } \\
\text { make a decision } \\
\text { Moral-based }\end{array}$ & $\begin{array}{l}\text { Moral based reasoning involves respecting } \\
\text { and protecting to the others while making a } \\
\text { decision }\end{array}$ & 7 \\
Emotive & $\begin{array}{l}\text { Emotive reasoning was characterized as the } \\
\text { use of emotions, specifically empathy and } \\
\text { sympathy }\end{array}$ & 5 & 9 \\
Intuitive & $\begin{array}{l}\text { Intuitive reasoning involves immediate reac- } \\
\text { tions to a particular SSI and may not be } \\
\text { rational }\end{array}$ & 4 & 7 \\
\hline
\end{tabular}


day; articles are published, and scientists give speeches. They say the virus particles hang in the air when we have a close position with the others, and there is highly a great chance for us to be infected. But the virus can also be transmitted by human interaction. Thus, in my opinion there is a less chance to be infected when we isolate ourselves in clean areas."

[PST \#2]: "I agree because I know how the COVID-19 spreads. The more we socialize, the faster it spreads. We see on the news if one person gets infected, s/he might infect other 30 people. So, it spreads faster in this way and it may cause crisis on my things. Therefore, I believe there has to be isolation."

[PST \#7]: "I definitely agree, because there is no other explanation why it spreads so quickly. I do not think there is another way to prevent it from spreading than staying home or lockdown. There is no treatment yet, and the best thing for now is staying in lockdown."

As seen from the quotations above, the PSTs explained their decision-making while using rational patterns and justifying them within COVID's genuine context, which is more expected in terms of their educational background and subject-matter knowledge. Almost all PSTs used similar statements given above while justifying their decisions with a variety of instruments by mainly addressing scientific facts.

\subsubsection{Moral-Based Decision-Making Mode}

Lee et al. (2012) defined moral-based compassion as having empathy and respecting for other human beings, while accordingly $N=7$ PSTs justified their isolation decision by revealing the empathy for the others and responsibility. This mode had the second-highest reference frequency $(N=9)$ among all the PSTs used as a decision-making mode. As can be inferred from the example quotations given below, PSTs were sensitive about others' well-being and infection within the context of COVID-19 by addressing issues like transmitting the virus, infecting others, public health, and ethical concerns. It was seen in quotations that most of PSTs approached this matter as an ethical issue that the right course of action requires individuals to care about others while following the orders of restrictions. For instance, PST \#24 addresses how important her behavior is in terms of public health and protecting the community, whereas PST \#25 highlights how risky is to behave irresponsibly especially in the case of being asymptomatic.

[PST \#4]: "No one would ever want to infect another person. But we do not know who is infected who is not. Thus, I believe the best thing to do is to stay at home." [PST \#24]: "I decided to stay home before even the curfew begins, to protect the others or to avoid infecting anyone else. I believe that's how all the other people should behave like."

[PST \#25]: "For example, if I was an asymptomatic person, there is a chance that I might still be a carrier and transmit it to the others. Even if I take that risk for my own, I cannot take that risk for the others. That's why social isolation should be applied."

\subsubsection{Emotive Decision-Making Mode}

In this decision-making mode, it was encountered with $N=5$ PSTs justifying their arguments based on a sense of care (Sadler \& Zeidler, 2005) of themselves or relatives', more 
likely from the emotional perspective rather than rationalistic. Emotive decision-making mode presents a care perspective which includes empathy and concern for the well-being of others. They elaborated their responses about how they emotionally could be affected unless they do not follow the orders. According to the example quotations are given below, PSTs who chose to use this decision-making mode are seemed to feel more likely responsible for others' infection or loss of their lives and used empathy towards the well-being of others which made them be more emotional in their decisions.

[PST \#3]: "When I heard people saying that everyone will be immune to that virus eventually, I was relieved. But when I started to hear from the people around that this person was infected and there was not an available spot in the hospital or even you cannot get any information regarding to that person's state of health, that really hit me emotionally. They still say that everyone will be immune to the virus. But isn't it to sacrifice some people's life or give up on their lives anyway?!"

[PST \#17]: "This might be the situation that I may not ever had the symptoms but still be infected. I might have assumed that I am not infected because we know that young people have less severe outcomes of this virus. I act responsible in this situation, I have elderly people in my life, my grandmother, my grandfather, I stay away from them considering these outcomes that I might let them to be infected. As of my responsibility for all, I think staying home is the smartest thing to do."

\subsubsection{Intuitive Decision-Making Mode}

As Sadler and Zeidler (2005) pointed out, intuitive decisions include immediate reactions to an ill-structured problem in an SSI case (Wu \& Tsai, 2007). Within our sample, $N=4$ PSTs were recorded to use an intuitive type of decision-making by providing immediate responses based on the text that they were given without providing justified arguments. An example quotation is given below, where PST \#20 tries to justify her own decision based on the sociological structure of the community without backing this argument with any kind of data or experience. Similar responses occurred in three other PSTs who used intuitive decision-making modes.

[PST \#20]: "Based on the text I've just read and social structure of our country, I believe social isolation is a need."

\subsection{Self-Reasoning Modes}

Quantified results for reasoning modes of pre-service teachers are provided at Table 3. Similar to Table 2, Table 3 shows the type of self-reasoning mode, its description, number of PSTs used this type, and number of references it was addressed within the mode. As mentioned above five of the categories, namely risk-perception, moral-based, economic oriented, religious oriented, and political oriented modes were derived from the literature, yet psychological oriented as new category emerged from the participant's responses. The summative operational definitions and exemplifier quotations of these modes are also provided below.

\subsubsection{Risk Perception Self-Reasoning Mode}

Defined as the discrepancies between the scientific and public perception of risk, low level of scientific knowledge of citizens by Lee (2012), risk perception self-reasoning mode 
Table 3 Pre-service biology teachers' self-reasoning modes

\begin{tabular}{|c|c|c|c|}
\hline Self-reasoning mode & Description & $\begin{array}{l}\text { Number of } \\
\text { PSTs }\end{array}$ & $\begin{array}{l}\text { Number of refer- } \\
\text { ences }\end{array}$ \\
\hline Risk perception & $\begin{array}{l}\text { Discrepancies between the scientific } \\
\text { and public perception of a risk, low } \\
\text { level of scientific knowledge of } \\
\text { citizens }\end{array}$ & 21 & 32 \\
\hline Moral-based & $\begin{array}{l}\text { Participants' care-based reasoning } \\
\text { about preventing themselves from } \\
\text { the risk of spreading or being } \\
\text { exposed to the virus }\end{array}$ & 19 & 38 \\
\hline Economic oriented & $\begin{array}{l}\text { Participants' reasoning about the eco- } \\
\text { nomic consequences of pandemic, } \\
\text { i.e., unemployment, loss of income, } \\
\text { and raise of prices }\end{array}$ & 15 & 21 \\
\hline Psychological oriented & $\begin{array}{l}\text { Participants' reasoning about their } \\
\text { own and beloved ones' psychologi- } \\
\text { cal state and the impact of the pan- } \\
\text { demic on individuals' well-being }\end{array}$ & 5 & 5 \\
\hline Religious oriented & $\begin{array}{l}\text { Participants' reasoning about their } \\
\text { religious beliefs }\end{array}$ & 2 & 2 \\
\hline Political oriented & $\begin{array}{l}\text { Participants' reasoning about the } \\
\text { management of the issue in terms of } \\
\text { policies, politicians, and politics }\end{array}$ & 1 & 2 \\
\hline
\end{tabular}

was listed as the highest among the others. 21 of the PSTs with more than one reference $(N=32)$ stated in different ways that the public opinion on following the orders is mostly related to the lack of understanding about the issues, namely low level of scientific knowledge in this context pandemic and the consequences. As can be inferred from the quotations given below, many PSTs addressed the lack of understanding of individuals and used these lacks understandings as motives for not approved behaviors.

[PST \#3]: "I have theory about this. I believe this is something related to that person's educational background. Because no matter how overpopulated Istanbul is as a city, other residents of the cities in Anatolia staying at home more than Istanbul people do, so I think could it be related to people's educational level? I do what I have been told, maybe it is because I study at a major (Biology Teaching) that is related to this situation, maybe that's why I'm that sensitive. I am the most nervous person at our house, and I am the person who tries to take all the precautions and I warn people around me all the time since the beginning. I believe that I should be the one who raise awareness. But you cannot deal with some other people, you cannot make them do something unless it is forbidden. Especially in Anatolia regions, in Black Sea region I have heard a lot of people dead. And when I speak them on the phone, they keep saying that I do not believe in this virus and this disease, nothing will ever happen to me..." [PST \#5]: "I think what they think is that they will not be affected that much. Their way of thinking is the ignorance of the matter, nothing would ever happen to them..."

According to the responses, as future teachers, most of PSTs believed the basis of these people's actions related to ignorance and low level of education, which needs to be improved in order to act rationally in the future. 


\subsubsection{Moral-Based Self-Reasoning Mode}

Similar to the moral-based decision-making mode (Lee, 2012; Lee et al., 2012), in moral-based self-reasoning mode PSTs revealed their care-based reasoning modes about preventing to exposition of the virus or being exposed to it. Consistent with the decision-making mode, this type of self-reasoning mode had the second-highest reference frequency $(N=38)$ with $N=19$ PSTs among all the types. On the quotations of many other PSTs, it was seen that PSTs were emphasizing potential transmitter roles of themselves in the act of defying the rules or measures; thus, their reasoning modes were shaped by moral-based concepts mainly protecting their family members and beloved ones' well-being. Exemplified quotations are provided below:

[PST \#4]: "I do not know how I would respond in the moment of a crisis. But from my own perspective, last thing I want to do is to spread the virus to the others when I'm sick."

[PST \#16]: "I'm saying that if s/he was exposed to the virus, we could all get sick and no one should be responsible for others' exposition. For example, I would feel terrible if I knew that I'm sick and responsible for others' sickness, that's because I was reckless to take the necessary precautions."

\subsubsection{Economic Oriented Self-Reasoning Mode}

It was seen that PSTs' reasoning about the economic consequences of the pandemic, i.e., unemployment, loss of income, raise of prices, increased inflation and currencies, devaluation of Turkish Lira, etc., and references was found quite high $(N=21)$. More than half of the PSTs $(N=15)$ raised their economy-related concerns about the pandemic within the context of a developing country. Many of them highlighted the fragileness of the economy and the possible economic impacts of the lockdowns on the economy, society as well as public health. Some of them also stated the insufficient financial support and aid of the Government for the ones who might be affected by the economic consequences. Exemplifier quotations are provided below:

[PST \#7]: "Small entities, businesses such as hairdressers, markets, etc. they all had to close their businesses. But they do not get any financial support or aid. We experience these also in our families, too. The man has 3 children, and his wife is unemployed, he was a barber. His business is closed but at the same time he needs to take care of his family. He could stay at home voluntarily but without any aid he had to leave his house and look for a job. Each person cares themselves and they do not want to put their life on jeopardy, but they had to leave their houses, because they had no other choice. Staying at home voluntarily is financially difficult. So, I think the government should make this policy mandate and should provide financial assistance to the people who are in need."

[PST \#17]: "The reason that our country did not applied whole country wide closing is the economic reasons behind. That is what most people think, as far as I know. At the same time, I say -yes economic destruction is another problem-. The government should apply some policies to minimize these effects at the same time protect the public health. But I know it is difficult to do that at the same time." 


\subsubsection{Psychological Oriented Self-Reasoning}

$N=5$ PSTs reasoning was found related to concerns of their own and beloved ones' psychological state and the impact of the pandemic on individuals' well-being. In the psychologically oriented arguments, problems concerning dealing with depression, anxiety, and stress were emphasized. The participants mostly highlighted that they do not know how to behave outside without the outbreak completely end.

[PST \#25]: "I believe we are going through tough times psychologically. It could be depressing to be inside all the time. But it would get worse if they (government) would be more flexible. Especially if the schools and universities would still be open, I would be very anxious about whether I was exposed to the virus or not. Or did I spread the virus? Did I touch somewhere, was it clean, did I then touch my face and so on, it would be more stressful and harder. So, if we all stay at home, we can all get through this process as soon as possible."

[PST \#18]: “It's their psychological state, getting bored at home, they can't find anything to do or to amuse themselves. Coping with stress. That is why they can take the risk of getting ill. Maybe they are not aware how serious this virus and consequences are. Many people do not even watch the news, because they say they do not feel good psychologically when they do."

\subsubsection{Religious Oriented Self-Reasoning}

It was found that few $(N=2)$ of the PSTs stated their reasoning according to their religious belief system. They tried to explain some behaviors and actions of others within the context of religion and the concept of death, specifically the Islamic belief system. Exemplifier quotations are provided below:

[PST \#4]: "I don't think we are so informed about these. We have a religious belief system, but we interpret these views differently. Most people have 'we will die anyway' perspective. Yes, we will all die. But I do not want to take anyone with me when I'm dying or maybe they will not die but I do not want to torture them with any disease."

[PST \#21]: "Another point of view of a particular group is that they say Allah (God) would protect us anyway. That's their way of thinking."

\subsubsection{Political Oriented}

$N=1$ PST tried to explain others' self-reasoning within the political system and views. The participant who generated political-oriented arguments considered that when people make decisions about social isolation, they are influenced by their political views.

[PST \#23]: "I believe the political views or sides of people have a lot to do with it.!"

\subsection{Persuasive Means}

Apart from the existent self-reasoning modes in the literature, we detected from the responses that PSTs used different types of persuasive means to convince another 
person in the case of opposition to their arguments or ideas. we found that PSTs might use hypothetical reasoning and use different tools when they were asked a hypothetical question or in the case of the nonexistence of an opposition. Thus, these detected means are classified as separate elements from the self-reasoning modes. The quantified results regarding this new category and their descriptions along with the number of respondents are provided in Table 4. The summative operational definitions and some exemplifier quotations of these means are also provided below.

\subsubsection{Moral-Based Persuasive Means}

It was found that the majority of the PSTs $(N=21)$ with more than one reference $(N=31)$ preferred to use moral-based persuasive means, that is participants' persuasion preference care-based reasoning and societal responsibilities, to persuade others those who are opposed to isolation ideas. These means included possible scenarios about infecting other people, especially in their own families, causing the death of other people, contributing to death rates of the virus, incidents happening in other countries, etc. Two exemplifier quotations are provided below:

[PST \#2]: "I would go emotionally to that person. I would ask, if related to a person who has chronic diseases, would you like to lose that person? Or would you like to be one who is responsible from other people's death? How many people could die or lose their parents just because of you? Something like that emotionally I would go, Turkish people love the drama."

[PST \#4]: "Yes of course you are free to go outside. No one would like to restrict you, but I would say while you are being free, you will be restricting others' freedom. So, if you are sick and you do not know about it, you might make other people sick. While you are defending your own freedom, you will restrict others' freedom. I could use this argument."

\subsubsection{Scientific Oriented}

Another type of mean that was used as the second-highest persuasion mean based on the scientific facts and scientific knowledge about the virus. It was found that $N=20$ PSTs with more than one reference $(N=30)$ preferred to use scientific content knowledge about the viruses to convince the others who are opposed to isolation. In teacher education programs, apart from the pedagogical knowledge, it is also aimed that the future teachers use and adapt the content knowledge they learned in school to apply in real-life settings as means to an informed community end. Consistent with this vision, scientifically oriented means that the PSTs used, included a variety of information regarding the virus structure such as how they spread, replication of the viruses, ideal conditions for the spreading, and possible reactions on health and public health. For instance, PST \#2 gives references to her Microbiology courses and the characteristics of the viruses whereas PST \#1 also references knowledge about viral replication to convince others from out-of-school environments.

[PST \#1]: "I would tell them about the viruses. How it reproduces or transmit to another cell, so we learnt about these at school. We have some knowledge to transfer to other people. I would tell these and try to inform that about how it reproduces, what kind of diseases it may cause or problems, etc." 


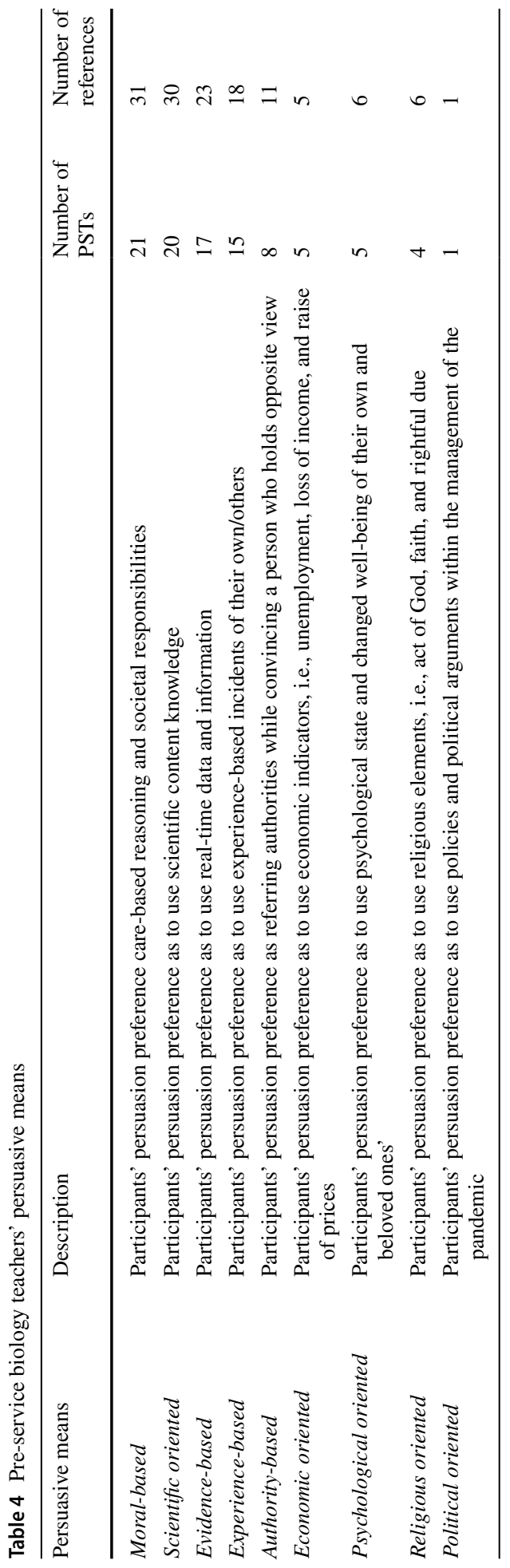


[PST \#2]: "So, I study Biology and took courses related to Microbiology. I know how the viruses spread. Do you know that even in one droplet moves $100 \mathrm{~m} / \mathrm{s}$ produced in a sneeze or in a cough 15 - 50 droplets are released, by yelling 15-50 droplets? I would say as if you knew all about these you said you do not need social isolation."

\subsubsection{Evidence-Based}

Most of PSTs $(N=17)$ preferred to use evidence-based information for convincing others about restrictions. The information they used included the info (infection rates, death rates, number of cases, duration of the illness, etc.) about the actual global virus incidents such as influenza, avian flu, SARS, and MERS, and the other countries' real-time data and information regarding the COVID-19 pandemic. It was also seen that some PSTs also used data regarding face-mask usage and the impact on the prevention of the illness. Considering the background of the participants, this type of means for persuasion along with the scientific means is expectable. PSTs seemed to use the subject-matter knowledge that they have in real-life settings and out-of-school environments. Two exemplifier quotations including some of these keywords are provided below. For instance, PST \#3 includes a variety of sources by addressing the importance of evidence-based decision-making and persuasion. Or elsewhere in PST \#4's quotation, she tries to highlight the severity of the situation by giving examples from other European countries' situations and comparing their context with her own country's context while emphasizing the weaknesses of the country in order to change others' minds.

[PST \#3]: "If I would come across with a that kind of person, I would use data and evidence. I would use the data of influenza, how many people was infected and how many died, how long did it take, etc. these precautions were taken yet this situation is different. Even too many precautions were taken in worldwide, thousands of people are dying, it is much worse than that. I would use these kinds of data and information." [PST \#4]: "I would show Italy as an example to them. Or Spain, or United Kingdom. They first said they will try the herd immunity policy, and everyone would be immune to the virus. But now, even their prime minister has been taken to the intensive care unit (ICU). Or in Italy, after they closed the schools, all the families moved to other parts of Italy, which caused them to spread the virus country-wide. I could use these examples. And our economy is not well, if we would become like Italy, we would not be handled to. It would be more difficult for us. I could also use China as an example. The government had a very strict policy about the restrictions. But eventually thanks to those policies they are back in their normal life again."

\subsubsection{Experience-Based}

It was found that $N=15$ PSTs used experience-based means of their own/others to persuade others. These experiences included their own experiences about COVID-19, including the states of their close ones who were infected, the people who were in ICUs, and the patients who were intubated. PSTs stated that they used these examples to make the others empathize and highlight the severity of the situation which would eventually make them follow the orders and isolate themselves.

[PST \#25]: “...For the ones who do not believe in stay home orders, I would use the example of my friends who got sick. I would give details about that sick person's 
health. I could warn them as this could happen to all of us. So, if we do not have to go outside, let's stay inside."

\subsubsection{Authority-Based}

$N=8$ of the PSTs was found to use references addressing to scientists, medical experts, ministry officials, and other authorities to convince the ones who are opposed to the isolation ideas. According to the quotations, many of them believed that the different authorities have a larger impact on changing people's ideas or convincing the groups of people with their wide knowledge. As in the case of PST \#5, people were advised to listen to scientists' suggestions working in the field, who has the potential to change others' minds more than others.

[PST \#5]: "I would advise them to listen experts, scientists on this matter. Because I think they will be more impressed on their talks than what I'm about to say or anyone who is less expert. But they might do what an infection disease expert say them to do. So, I think, I could use an authority as a reference."

\subsubsection{Economic-Oriented}

$N=5$ PSTs were found to use economic indicators and economic harm during the pandemic by using the terms such as unemployment, loss of income, and raise of prices. in order to persuade others. By using these terms PSTs expected them to understand the notion that the longer of this battle with the virus remains, the more harm the economy will get. An exemplifier quotation regarding to that argument is provided below:

[PST \#23]: "I could go with the economic situation and how this pandemic deeply affected the economy. Sometimes it is better people to experience and see themselves when they have the empathy. I would ask that person to make a comparison of preand post-state of his/her own economical state."

\subsubsection{Psychological Oriented}

$N=5$ PSTs used psychological states and changed the well-being of their own / beloved ones in order to convince others. PSTs highlighted in their responses that these types of effects were experienced by most of the people so that everyone should follow the orders to make this period shorter. They used psychological terms to convince themselves and others, such as perseverance, patience, being positive, optimism, depression, denial, acceptance, motivation, and determination. An exemplifier quotation regarding that argument is provided below:

[PST \#13]: "I would tell them to persevere and to be patient. This situation is hard for all of us. But the more we persevere and be patient, it could be better. It is exhausting for all of us. We all want to see and meet other people; we are all bored. But you need to think of the others. If we all want this go away and get back to the way we used to be, we need to stick to the precautions." 


\subsubsection{Religious Oriented}

$N=4$ of the PSTs used religious elements, i.e., the act of God, faith, and rightful due, in order to convince those who they think they could only be convinced by the help of their religious beliefs. They related religious terms with the pandemic situation's severity and expected them to understand and prioritize public health within the context of religion. An exemplifier quotation regarding that argument is provided below:

[PST \#17]: "It's not just your health is the issue here. Because you spread the virus, it is your responsibility and its rightful due in terms of Islam. We could use this argument to those who object."

\subsubsection{Political Oriented}

$N=1$ PST used politics as a persuasion tool in terms of policies embraced during the pandemic and governmental management of the pandemic. The political division in terms of political opinions was emphasized and associated with the policies of public health. The sole exemplifier quotation regarding that argument is provided below:

[PST \#23]: "Even within this situation it becomes political. It is ridiculous. We are dealing with life here. But still society divided into two giant groups, which is really bad. I would ask these people to watch and learn from these two different perspectives and broadcasts and then make an interpretation, not just believing it as it is or without making any inquiry. I would advise them to be more open-minded for different ideas."

\section{Discussions and Educational Implications}

To address the research questions set for this study, the findings are discussed with respect to PST' decision-making mode, informal reasoning modes, and persuasive means.

\subsection{Decision-Making Modes}

The present study revealed that the majority of the participants (60\%) made rationalistic based decisions about COVID-19 and social isolation. Previous research also indicated that individuals tend to make decision based on rationalistic reasoning (Sadler \& Zeidler, 2005; Wu \& Tsai, 2011). Moral-based decision-making, which is second highest frequency among all decision-making modes, that is also specific to the issue. While moral based category was observed as reasoning mode in previous studies (e.g., Topçu et al., 2011), the category has emerged both as decision-making mode and reasoning mode in the present study. There may be several reasons for the new decision-making category. First, COVID19 and social isolation is a real-time and dynamic issue and affecting people's daily life directly. Particularly, in media and social media have always announced that people should "stay-home" and "protect yourself and loved ones from COVID-19". The reason for the new category in the present study can also be related to participants' enhanced social responsibility due to increasing the number of case and death. 
In the context of COVID-19 and social isolation, the participants' decision-making on the issue were influenced by religious and political concerns. However, few participants utilized the two reasoning categories in the present study; it should be noted that the factors related political (Ozturk \& Yilmaz-Tuzun, 2017) and religious (Topçu et al., 2011) influence individuals' informal reasoning in the context of SSI in Turkey.

\subsection{Self-Reasoning Modes}

The result revealed that following categories regarding self-reasoning mode were identified: risk perception, moral based, economic oriented, psychological oriented, religious oriented, and political oriented (Fig. 2). Most of categories in this study were found in the literature except for psychological oriented categories, which was newly identified in the present study. The new category may be emerged for several reasons. Reiss (2020) pointed out that COVID-19 outbreak has been creation of social anxiety. The situation can be assessed as significant component in decision-making about the issue. Also, Lee (2012) stated that reasoning on health issues is likely to evoke psychological responses rather than rationalistic ones. Most of participants have preferred to develop the arguments related to their risk perception in the self-reasoning mode. According to Lee (2012) public risk perception which means low level of scientific knowledge of citizens, could directly influence on decision-making regarding health issue such as COVID-19. Also, this type of risk perception may be stemmed from misconception on transmission of the virus (ibid.). In this sense Science is related to sociocultural as well as inner psychological backgrounds, making it extremely difficult to understand health problems (Lee, 2012).

Moral based reasoning was a common category for each reasoning group (decisionmaking, self-reasoning, and persuasive means). Morality literally means that principles

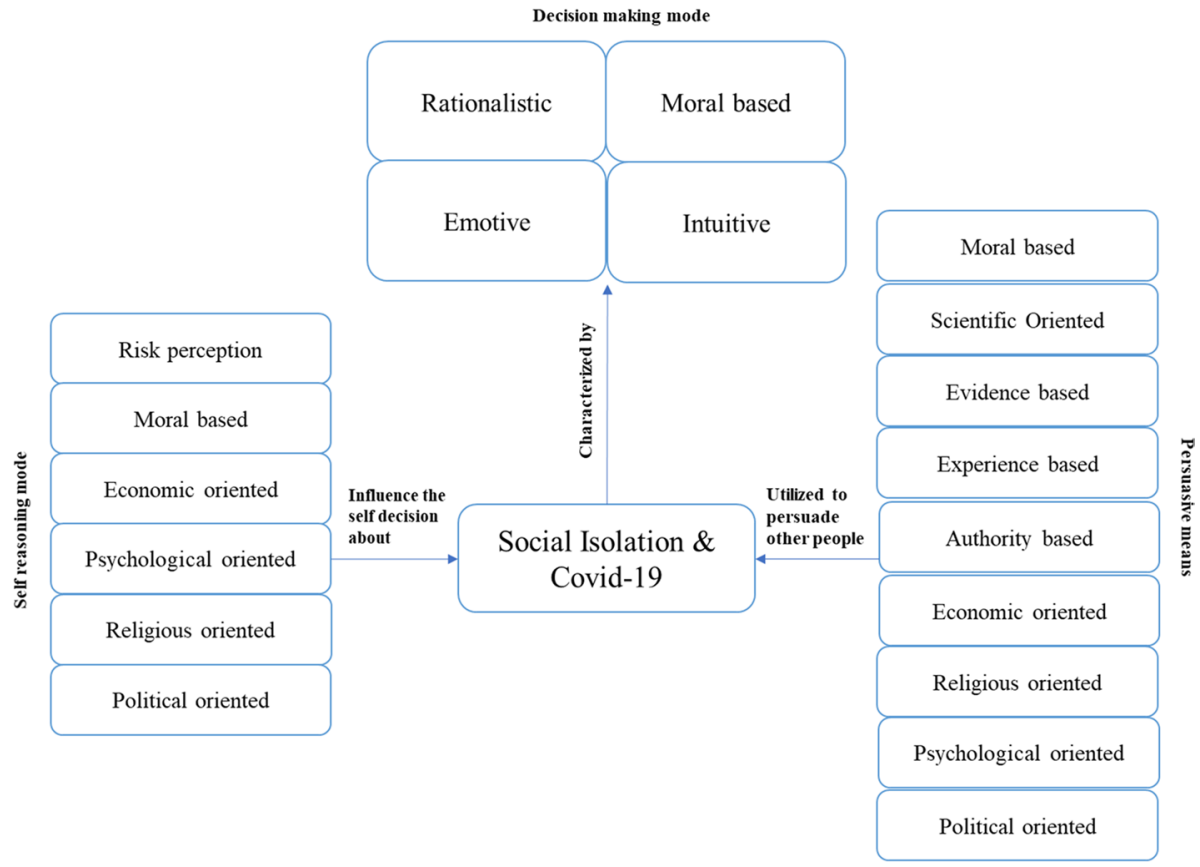

Fig. 2 The outcome of informal reasoning regarding COVID-19 and social isolation 
concerning the distinction between right and wrong or good and bad behavior. In this study, while moral based reasoning appears in all three categories, it is also one of the most frequently used arguments of informal reasoning in each category. Individuals made decisions about COVID-19 and social isolation by considering the health and safety of others, indicating that their main concern was social responsibility and losing loved ones. This result is consistent with the previous studies of SSI (Bell \& Lederman, 2003; Pedretti, 1999; Sadler \& Zeidler, 2004). Moreover, moral based reasoning has been utilized in dealing with the issue that based on science-society-health and directly affect our lives.

\subsection{Persuasive Means}

The present study revealed that the participants tend to use different reasoning means when trying to persuade someone to believe their opinions in the context of COVID-19 and social isolation. Moral-based, scientific-oriented, evidence-based, experience-based, and authority-based arguments were more commonly used than other persuasive arguments. Apart from other categories, only moral-based arguments were utilized as both self-reasoning tools and persuasive means. The participants did not use scientific-oriented arguments about self-reasoning on social isolation and COVID-19. However, the scientific-oriented arguments were one of the most produced arguments to convince someone about the issue. Most of the participants stated that the data of current and previous pandemics (e.g., swine flu) would have been utilized to convince someone of their ideas about social isolation and COVID-19. Moreover, experience-based arguments which were newly identified in the study. Personal experience was found as one of the factors that influenced informal reasoning (Sadler \& Zeidler, 2005; Topçu et al., 2011). However, experience-based arguments in the present study mean developing arguments based on both their own experience and other people's experience around the world. In this context, the participants mentioned the use of the videos on COVID-19 patient experiences, especially the painful ones, as tools for persuading someone. Furthermore, experience-based arguments are also considered persuasion means rather than the factor affecting decision-making in the study. The type of arguments may be specific to real-time SSI, because they have not emerged in the previous studies regarding SSI. Finally, the argument that is revealed specific to persuasive means is authority based. The emergent category could be causally related to sociocultural components of the society. Because Individualistic and anti-authoritarian culture is observed in Western societies while in non-Western societies, the authority (such as teachers, parents, and experts) holds a significant place in the lives of people as observed in China and Turkey (Chan \& Elliott, 2004). In the research, scientists and physicians were considered authorities whose views about COVID-19 and the relevant social isolation are obtained and subsequently implemented to serve the purpose of persuasion.

The structure of psychological oriented arguments generated by the participants differs according to the reasoning category used. For instance, when self-reasoning on COVID-19 and isolation, they were focusing on the negative sides of psychology (e.g., anxiety). While the arguments were developed for the persuasive means, the positive side of psychology (e.g., well-being of their own) was considered.

In conclusion, interactions between science, sociocultural context, and psychological process in reasoning was clearly observed in real-time SSI (the case of COVID-19 and social isolation) rather than other SSI (e.g., nuclear power plant). Also, the most frequently used reasoning mode was moral based. The category refers to protecting yourself and loved ones. The study presents multidimensional nature of real-time health-related SSI. 
Recent reform documents (NGSS Lead States, 2013; Ministry of National Education of Turkey [MONE], 2018; National Research Council, 1996) have highlighted students' ability to make their decisions on SSI and suggested that teachers should have responsibility for preparing students for the decision-making processes (Wu \& Tsai, 2007). In this sense, how PSTs, whom they are considered future teachers, discuss and decide on real-time SSI have become important issues. PSTs must have knowledge about discussing and making decisions regarding their ideas to make conclusions about informal reasoning and scientific facts. To accomplish this, science educators must assist PSTs to be informed of the informal reasoning and give them insight into SSI information. During their education and training, SSI specific courses may be delivered to PSTs. Karpudewan and Roth (2018) discussed that evidence-based and scientific reasoning is better than other reasoning modes. When designing such an SSI course for PSTs, the focus of the course should be promoting rationalistic decision-making mode, evidence based and scientific oriented reasoning modes. They explained the reason behind their rationale as evidence and scientific-based reasoning support informal reasoning. Also, the importance of the reasoning quality should be emphasized since it is an indicator for PST's improved SSI-related informal reasoning (Karpudewan \& Roth, 2018). Scientific literacy required the competency to rationally participate in public debates by providing relevant evidence. For this reason, PSTs should be aware of multiple dimensions of SSI and make informed decision related to SSI. PSTs could develop this kind of reasoning not in a theoretical way but by engaging with real issues associated to individuals' everyday concerns such as COVID-19. The teacher training course which focusing on SSI should provide PSTs with an effective context in which to deal with real issues that are not far from their daily lives.

Furthermore, additional research in various cultures can be carried out to explore the modes of reasoning of individuals with respect to real-time SSI to unfold the impact of cultural dynamics during the development of relevant arguments.

Regarding the self-reasoning mode, PSTs used risk perception, moral based, economic oriented, psychological, religious, and political oriented arguments. Most of categories of reasoning were found in the previous literature (Sadler \& Zeidler, 2005; Ozturk \& Yilmaz-Tuzun, 2017; Wu \& Tsai, 2011). But psychological oriented category emerged as a new reasoning mode for SSI. The result of the study is likely due to nature of selected issue. Another noteworthy result is the category of risk perception that has highest frequency in self-reasoning mode. Teacher training programs are an effective approach to address various issues faced by PSTs in order to assist PSTs better deal with their fears concerning threats as well as psychological circumstances. These approaches allow teachers and instructors to manage the risk-oriented needs of their prospective learners more effectively by learning more about risks and handling psychology. For example, some participants considered that social distancing and isolation are not necessary for preventing COVID-19 contagious. They do not believe that COVID-19 is spread mainly through close contact from person to person. Thus, the risk has been taken by going out or by not following the lockdown orders. According to Lee (2012), the public perception of risk mainly stemmed from lack of understanding about the issues and low level of scientific knowledge. In order to help PSTs easily manage their risk perceptions, the SSI courses in teacher training programs can be organized for PSTs to evaluate these issues from multi perspectives. Having more information about the issue and the risks might enable PSTs to feel confident while teaching SSI in their future classroom. Also, the situation can provide effective context for PSTs to reflect their risk-oriented concerns. 
Finally, participants mostly preferred to use as persuasion means which are moral based, scientific oriented, evidence based, experience based, and authority based. The results of the study indicate that the arguments used by the participants in self-reasoning and persuading someone about COVID-19 and social isolation are entirely different. For instance, as provided below, PST \#10 used rationalistic argument in self-reasoning while s/he preferred emotional argument when convincing someone else.

[PST \#10]: "we should definitely stay home since all the measures and the government officials require us to do so. And in the case of getting the flu for example, we are more careful with our eating habits as well as isolating ourselves from others. This disease is something like that. We should isolate ourselves in order to be safe, even if I had to go out for working or different reasons, I would take the necessary precautions since the data shows how contagious this is." (rationalistic) [PST \#10]: “... I would say those youngsters who go outside and not following the orders, that you must think of your mother, father, grandparents first even if you don't think about yourself, you could be responsible of their illnesses and maybe their death." (emotional)

Moreover, these results were consistent with the argumentative theory of reasoning (Mercier et al., 2017), which emphasized that there is difference between the argument that individuals use self-reasoning and the prefer to persuade others through argumentation. To understand the sources of the differences, further research is suggested to address this important issue with different sample and levels (such as elementary school or university). On the other hand, the pattern of self-reasoning revealed some of critical characteristics of system 1 (dual process theory) such as intuitive and pragmatic comments about the issue. In contrast, the persuasion means appeared to be consistent with the production of system 2 such as scientific and evidence-based reasoning. However, further studies are needed to examine this relationship.

It should be noted that there are few limitations of this work. First, the issue used in the research was COVID-19 and social isolation. Follow-up studies should continue to explore whether informal reasoning process may differ across various issues related to COVID-19 such as COVID-19 vaccination and COVID-19 measures. The second limitation is the coding process that was used in the study. Given the nature of the topic (i.e., pandemic and social isolation), the coding process is of paramount importance. In this study, we reached an agreement of $90 \%$ among the coders across emergent codes. But this does not guarantee the identification of latent meanings of all the data. Future work should consider using a third independent researcher/coder in addition to the researchers when analyzing the data to elaborate in-depth meanings of the informal reasoning about this issue.

\section{Appendix. The SSI passage about COVID-19 given to pre-service biology teachers}

\section{Days with Coronavirus Around the World}

Coronaviruses $(\mathrm{CoV})$ are a large family of viruses that cause different illnesses, from the common cold to more serious diseases such as severe acute respiratory syndrome (SARSCoV). On December 31, 2019, the World Health Organization (WHO) China Country 
Office reported cases of pneumonia of an unknown cause in Wuhan, China. On January 7 , 2020, it was determined that this disease was caused by a novel coronavirus (2019-nCoV) that was not previously detected in humans. Later, the name of the 2019-nCoV disease was accepted as COVID-19, and the virus was named SARS-CoV-2 due to its close similarity to SARS CoV.

On December 31, 2019, WHO declared that this virus caused a pandemic. On January 23, 2020, the full quarantine application was started in the Wuhan region. In February, strict quarantine practices continued in many regions of China, and serious sanctions (arrest, imprisonment, house arrest, high amounts of fines, etc.) started to be imposed on citizens who did not comply with the quarantine rules.

In line with the first cases detected on February 19, 2020, Iran was declared as the center of the global pandemic after China. In Iran, a large-scale quarantine has not been declared, and the decision to stay at home is left to individuals' own will.

It is known that the first cases began to appear on January 30, 2020, in Italy, which was one of the countries most affected by the virus with the number of cases and death toll. On February 21, especially with the increasing numbers and deaths in the Lombardy region, the quarantine application was started on February 21,2020 . In this process, it is known that especially with the closure of schools and workplaces, people living in this region helped spreading the virus by going to different parts of Italy and as of March 8, 2020, more than 16 million people were already infected. In addition, on this date, quarantine was started in the whole country.

In Spain, which was the country with the highest number of cases and deaths after Italy in Europe, when it was reported that there were thousands of cases in 50 different regions of the country on March 13, a 15-day state of emergency was implemented, and partial quarantine was started on March 14, 2020. At the end of the 15 days of partial quarantine, on March 29, 2020, it was decided that all people except the workers of supermarkets, pharmacists, and medical experts should stay at home and it was forbidden to go out on the streets except for basic needs.

United Kingdom, which tried the policy that did not include any measures other than the basic measures called "herd immunity" in the days when the virus first started to appear, then switched to partial quarantine on March 23, 2020, with the rapidly increasing number of cases and deaths. In the USA, Donald Trump proposed quarantine in New York, known as the epicenter of the pandemic then, and two states. While a general decision cannot be made in line with the state system in the country, each state continued to fight the pandemic with mandatory quarantine or "stay home" calls according to statewide rules.

Whereas in the northern Europe, there was a quite different situation. There were no restrictions on daily life in Sweden. People were free to roam in the streets and continue to go to restaurants and cafes. While more than 6800 cases have been detected in the country so far (March 30), the number of deaths has exceeded 400. Prime Minister Lofven stated that it is not necessary to take a general measure in the country, and everyone can take their own measures. The Swedish government was thought to be slowly implementing "herd immunity." There was a similar picture in Belarus. While people continue their daily life there, no restriction on collective activities has been imposed. Belarus President Aleksandr Lukashenko stated that as a country, they struggled against different viruses before that, and that they can also fight against it. He noted that panic may be more dangerous than the virus itself. 
While the advantages and disadvantages of quarantine and social isolation practices are being discussed around the world, economic, social, and psychological consequences are seen in different ways in countries that took or did not take these measures. It is feared that the pandemic will negatively affect the global economy and will sharply increase unemployment rates. Even today, many people have lost their jobs and income. One of the most important concerns of these times is the fact that the world will struggle with a new economic crisis after the corona pandemic. While people in countries that have made social isolation, decisions are closed at home; this situation can trigger feelings of fear, anxiety, and panic in people. It seems that it will take longer for the society to recover again after the corona pandemic and social isolation, to go out on the streets without fear, and to return to normal lives.

\section{Declaration}

Conflict of Interest The authors have no conflicts of interest to disclose.

\section{References}

Bayram-Jacobs, D., Henze, I., Evagorou, M., Shwartz, Y., Aschim, E. L., Alcaraz-Dominguez, S., et al. (2019). Science teachers' pedagogical content knowledge development during enactment of socioscientific curriculum materials. Journal of Research in Science Teaching, 56, 1207-1233.

Bell, R. L., \& Lederman, N. G. (2003). Understandings of the nature of science and decision making on science and technology based issues. Science Education, 87(3), 352-377.

Böttcher, F., \& Meisert, A. (2013). Effects of direct and indirect instruction on fostering decision-making competence in socioscientific issues. Research in Science Education, 43(2), 479-506.

Chan, K. W., \& Elliott, R. G. (2004). Epistemological beliefs across cultures: Critique and analysis of beliefs structure studies. Educational Psychology, 24(2), 123-142.

Dawson, V., \& Venville, G. J. (2009). High-school students' informal reasoning and argumentation about biotechnology: An indicator of scientific literacy? International Journal of Science Education, 31(11), $1421-1445$.

DeBoer, G. E. (2000). Scientific literacy: Another look at its historical and contemporary meanings and its relationship to science education reform. Journal of Research in Science Teaching, 37, 582-601.

Demirbilek, Y., Pehlivantürk, G., Özgüler, Z. Ö., \& Meşe, E. A. (2020). COVID-19 outbreak control, example of ministry of health of Turkey. Turkish Journal of Medical Sciences, 50, 489-494.

di Sessa, A. A. (1993). Toward an epistemology of physics. Cognition and Instruction, 10(2-3), 105-225. Responses to commentary, 261-280.

Eisenhart, M., Finkel, E., \& Marion, S. F. (1996). Creating the conditions for scientific literacy: A reexamination. American Educational Research Journal, 33, 261-295.

Evans, J. S. B. (2002). Logic and human reasoning: An assessment of the deduction paradigm. Psychological Bulletin, 128(6), 978.

Evans, J. S. B. (2003). In two minds: Dual-process accounts of reasoning. Trends in Cognitive Sciences, 7(10), 454-459.

Evans, J. S. B., \& Thompson, V. A. (2004). Informal reasoning: Theory and method. Canadian Journal of Experimental Psychology, 58(2), 69.

Fang, S. C., Hsu, Y. S., \& Lin, S. S. (2019). Conceptualizing socioscientific decision making from a review of research in science education. International Journal of Science and Mathematics Education, 17(3), 427-448.

Fensham, P. (2012). Preparing citizens for a complex world: The grand challenge of teaching socio-scientific issues in science education. In A. Zeyer \& R. Kyburz-Graber (Eds.), Science/environment/health: Towards a renewed pedagogy for science education (pp. 7-29). Springer.

Fooladi, E. C. (2020). Between education and opinion-making. Science \& Education, 29(5), 1117-1138.

Glaser, B., \& Strauss, A. (1967). The discovery of grounded theory. Aldine Publishing Company. 
Güner, H. R., Hasanoğlu, I., \& Aktaş, F. (2020). COVID-19: Prevention and control measures in community. Turkish Journal of Medical Sciences, 50, 571-577.

Hogarth, R. M. (2005). Deciding analytically or trusting your intuition? The advantages and disadvantages of analytic and intuitive thought. In T. Betsch \& S. Haberstroh (Eds.), The routines of decision making (pp. 67-82). Lawrence Erlbaum Associates Publishers.

Holyoak, K. J., \& Morrison, R. G. (Eds.). (2005). The Cambridge handbook of thinking and reasoning (Vol. 137). Cambridge University Press.

Hurd, P. D. (1998). Scientific literacy: New minds for a changing world. Science Education, 82, 407-416.

Jho, H., Yoon, H. G., \& Kim, M. (2014). The relationship of science knowledge, attitude and decision making on socio-scientific issues: The case study of students' debates on a nuclear power plant in Korea. Science \& Education, 23(5), 1131-1151.

Jonassen, D. H., \& Kim, B. (2010). Arguing to learn and learning to argue: Design justifications and guidelines. Educational Technology Research and Development, 58(4), 439-457.

Karpudewan, M., \& Roth, W. M. (2018). Changes in primary students' informal reasoning during an environment-related curriculum on socio-scientific issues. International Journal of Science and Mathematics Education, 16(3), 401-419.

Kolst $\varnothing$, S. D. (2006). Patterns in students' argumentation confronted with a risk-focused socio-scientific issue. International Journal of Science Education, 28(14), 1689-1716.

Kuhn, D. (1991). The Skills of Argument. Cambridge University Press.

Kuhn, D. (1993). Science argument: Implications for teaching and learning scientific thinking. Science Education, 77(3), 319-337.

Ladachart, L., \& Ladachart, L. (2021). Preservice biology teachers' decision-making and informal reasoning about culture-basedsocioscientific issues. International Journal of Science Education, 43(5), 641-671.

Leach, M., \& Scoones, I. (2013). The social and political lives of zoonotic disease models: Narratives, science and policy. Social Science \& Medicine, 88, 10-17.

Lee, Y. C. (2007). Developing decision-making skills for socio-scientific issues. Journal of Biological Education, 41(4), 170-177.

Lee, Y. C. (2012). Socio-scientific issues in health contexts: Treading a rugged terrain. International Journal of Science Education, 34(3), 459-483.

Lee, Y. C., \& Grace, M. (2012). Students' reasoning and decision making about a socioscientific issue: A cross-context comparison. Science Education, 96(5), 787-807.

Lee, H., Chang, H., Choi, K., Kim, S. W., \& Zeidler, D. L. (2012). Developing character and values for global citizens: Analysis of pre-service science teachers' moral reasoning on socioscientific issues. International Journal of Science Education, 34(6), 925-953.

Lincoln, Y. S., \& Guba, E. G. (1985). Naturalistic Inquiry. Sage Publications.

Liu, S., \& Lawrenz, F. (2018). Exploring college students' cognitive patterns during reasoning. International Journal of Science Education, 40(14), 1736-1754.

Liu, S. Y., Lin, C. S., \& Tsai, C. C. (2011). College students' scientific epistemological views and thinking patterns in socioscientific decision making. Science Education, 95(3), 497-517.

Lundström, M., Ekborg, M., \& Ideland, M. (2012). To vaccinate or not to vaccinate: How teenagers justified their decision. Cultural Studies of Science Education, 7(1), 193-221.

Lyons, A. C., \& Chamberlain, K. (2006). Health psychology: A critical introduction. Cambridge University Press.

Mason, L., \& Scirica, F. (2006). Prediction of students' argumentation skills about controversial topics by epistemological understanding. Learning and Instruction, 16(5), 492-509.

Means, M. L., \& Voss, J. F. (1996). Who reasons well? Two studies of informal reasoning among children of different grade, ability, and knowledge levels. Cognition and Instruction, 14(2), 139-178.

Mercier, H., Boudry, M., Paglieri, F., \& Trouche, E. (2017). Natural-born arguers: Teaching how to make the best of our reasoning abilities. Educational Psychologist, 52(1), 1-16.

Ministry of National Education of Turkey (MONE). (2018). Biology curriculum of high schools (9th12th Grades). Board of Education.

National Research Council. (1996). National science education standards. National Academy Press.

NGSS Lead States. (2013). Next generation science standards. For states, by states. National Academy Press.

Norris, S. P., \& Phillips, L. M. (2003). How literacy in its fundamental sense is central to scientific literacy. Science Education, 87(2), 224-240. 
Ohm, E. (2005). The relationship between formal and informal reasoning (Doctoral dissertation). Retrieved from http://citeseerx.ist.psu.edu/viewdoc/download?doi=10.1.1.86.744\&rep=rep1\&type= pdf. Accessed 12 March 2021.

Ozturk, N., \& Yilmaz-Tuzun, O. (2017). Preservice science teachers' epistemological beliefs and informal reasoning regarding socioscientific issues. Research in Science Education, 47(6), 1275-1304.

Patton, M. Q. (1990). Qualitative evaluation and research methods. SAGE Publications Inc.

Pedretti, E. (1999). Decision making and STS education: Exploring scientific knowledge and social responsibility in schools and science centers through an issues-based approach. School Science and Mathematics, 99(4), 174-181.

Ratcliffe, M., \& Grace, M. (2003). Science education for citizenship. Open University Press.

Reiss, M. J. (2020). Science education in the light of COVID-19. Science \& Education, 29(4), 1079-1092.

Rennie, L. J., Goodrum, D., \& Hackling, M. (2001). Science teaching and learning in Australian schools: Results of a national study. Research in Science Education, 31(4), 455-498.

Romine, W. L., Sadler, T. D., \& Kinslow, A. T. (2017). Assessment of scientific literacy: Development and validation of the Quantitative Assessment of Socio-Scientific Reasoning (QuASSR). Journal of Research in Science Teaching, 54(2), 274-295.

Sadler, T. D. (2004). Informal reasoning regarding socioscientific issues: A critical review of research. Journal of Research in Science Teaching: The Official Journal of the National Association for Research in Science Teaching, 41(5), 513-536.

Sadler, T. D., \& Zeidler, D. L. (2004). The morality of socioscientific issues: Construal and resolution of genetic engineering dilemmas. Science Education, 88(1), 4-27.

Sadler, T. D., \& Zeidler, D. L. (2005). Patterns of informal reasoning in the context of socioscientific decision making. Journal of Research in Science Teaching: The Official Journal of the National Association for Research in Science Teaching, 42(1), 112-138.

Sadler, T. D., \& Dawson, V. (2012). Socio-scientific issues in science education: Contexts for the promotion of key learning outcomes. In B. J. Fraser, K. G. Tobin, \& C. J. McRobbie (Eds.), Second international handbook of science education (pp. 799-809). Springer.

Sadler, T. D., Barab, S. A., \& Scott, B. (2007). What do students gain by engaging in socioscientific inquiry? Research in Science Education, 37(4), 371-391.

Saribas, D., \& Çetinkaya, E. (2020). Pre-service teachers' analysis of claims about COVID-19 in an online course. Science \& Education, 30(2), 235-266.

Shaw, V. F. (1996). The cognitive processes in informal reasoning. Thinking \& Reasoning, 2(1), 51-80.

Teig, N., \& Scherer, R. (2016). Bringing formal and informal reasoning together-A new era of assessment? Frontiers in Sychology, 7, 1097.

Tidemand, S., \& Nielsen, J. A. (2017). The role of socioscientific issues in biology teaching: From the perspective of teachers. International Journal of Science Education, 39(1), 44-61.

Topçu, M. S., Yılmaz-Tüzün, Ö., \& Sadler, T. D. (2011). Turkish preservice science teachers' informal reasoning regarding socioscientific issues and the factors influencing their informal reasoning. Journal of Science Teacher Education, 22(4), 313-332.

Turkish Ministry of Health. (2021). Turkey daily Covid-19 cases. Web access link: https://covid19.saglik.gov.tr/TR-66935/genel-koronavirus-tablosu.html. Accessed 14 March 2021.

Tweney, R. D. (1991). Informal reasoning in science. In J. F. Voss, D. N. Perkins, \& J. W. Segal (Eds.), Informal reasoning and education (pp. 3-16). Erlbaum.

Walker, K. A., \& Zeidler, D. L. (2007). Promoting discourse about socioscientific issues through scaffolded inquiry. International Journal of Science Education, 29(11), 1387-1410.

Wason, P. C., \& Johnson-Laird, P. N. (1972). Psychology of reasoning: Structure and content. Harvard University Press.

Wiblom, J., Andrée, M., \& Rundgren, C. J. (2020). Navigating alarming media messages about nutrition and health. Science \& Education, 29(1), 75-100.

World Health Organization (2020). Managing the COVID-19 infodemic: Promoting healthy behaviours and mitigating the harm from misinformation and disinformation. https://www.who.int/news/item/ 23-09-2020-managing-the-covid-19-infodemic-promoting-healthy-behaviours-and-mitigating-theharm-from-misinformation-and-disinformation. Accessed 6 March 2021.

Wu, Y., \& Tsai, C.-C. (2007). High school students' informal reasoning on a socio-scientific issue: Qualitative and quantitative analyses. International Journal of Science Education, 29(9), 1163-1187.

Wu, Y. T., \& Tsai, C. C. (2011). High school students' informal reasoning regarding a socio-scientific issue, with relation to scientific epistemological beliefs and cognitive structures. International Journal of Science Education, 33(3), 371-400. 
Yang, F. Y., \& Anderson, O. R. (2003). Senior high school students' preference and reasoning modes about nuclear energy use. International Journal of Science Education, 25, 689-725.

Zangori, L., Ke, L., Sadler, T. D., \& Peel, A. (2020). Exploring primary students causal reasoning about ecosystems. International Journal of Science Education, 42(11), 1799-1817.

Zeidler, D. L. (2014). Socioscientific issues as a curriculum emphasis: Theory, research, and practice. In N. G. Lederman \& S. K. Abell (Eds.), Handbook of research on science education (Vol. II, pp. 697-726). Routledge.

Zeidler, D. L., \& Keefer, M. (2003). The role of moral reasoning and the status of socio-scientific issues in science education. In D. L. Zeidler (Ed.), The role of moral reasoning on socio-scientific issues and discourse in science education (pp. 7-38). Kluwer Academic Publishers.

Zeidler, D. L., Walker, K. A., Ackett, W. A., \& Simmons, M. L. (2002). Tangled up in views: Beliefs in the nature of science and responses to socioscientific dilemmas. Science Education, 86, 343-367.

Zeidler, D. L., Sadler, T. D., Simmons, M. L., \& Howes, E. V. (2005). Beyond STS: A research-based framework for socioscientific issues education. Science Education, 89(3), 357-377.

Zohar, A., \& Nemet, F. (2002). Fostering students' knowledge and argumentation skills through dilemmas in human genetics. Journal of Research in Science Teaching: The Official Journal of the National Association for Research in Science Teaching, 39(1), 35-62.

Publisher's Note Springer Nature remains neutral with regard to jurisdictional claims in published maps and institutional affiliations. 